\title{
Transesterification of waste frying oil using a zinc aluminate catalyst
}

\author{
C.T. Alves ${ }^{\text {a, } *}$, A. Oliveira ${ }^{a}$, S.A.V. Carneiro ${ }^{\text {a }}$, A.G. Silva ${ }^{\text {b }}$, H.M.C. Andrade ${ }^{\text {b }}$, S.A.B. Vieira de Melo ${ }^{\text {a }}$, E.A. Torres ${ }^{\text {a }}$ \\ a Programa de Engenharia Industrial - Escola Politécnica - Universidade Federal da Bahia, Rua Prof. Aristides Novis, 2, Federação, 40210-630, Salvador, Bahia, Brazil \\ ${ }^{\mathrm{b}}$ INCT - Energia e Ambiente and Instituto de Química - Universidade Federal da Bahia, Rua Barão de Geremoabo, s/n, Salvador, Bahia, Brazil
}

\section{A R T I C L E I N F O}

\section{Article history:}

Received 8 September 2011

Received in revised form 16 January 2012

Accepted 4 July 2012

Available online 31 July 2012

\section{Keywords}

Biodiesel

Transesterification

Waste frying oil

Zinc aluminate

\begin{abstract}
A B S T R A C T
The transesterification of waste frying oil (WFO) with methanol and ethanol was studied in a batch reactor using a zinc aluminate catalyst prepared by the combustion reaction method. The reaction runs were carried out for 2 hours, using alcohol:oil molar ratio of $40: 1$, temperature range of $60-200{ }^{\circ} \mathrm{C}$, catalyst ratio of $1-10 \%$ wt., under $700 \mathrm{rpm}$ stirring. The catalyst was characterized by XRD, EDX, TG, FTIR, $\mathrm{N}_{2}$ physisorption, $\mathrm{NH}_{3}-$ and $\mathrm{CO}_{2}$-TPD. The catalyst showed a normal spinel structure and acid character (Lewis acid), in spite of the presence of both strong acid and base sites. Methyl and ethyl esters yields higher than 95\% were obtained at 150 and $200{ }^{\circ} \mathrm{C}$ and the catalyst was recovered and reused in 3 reaction cycles, without significant loss of activity.
\end{abstract}

(c) 2012 Elsevier B.V. All rights reserved.

\section{Introduction}

The concerns on the negative impacts of fossil fuels on the climate and the serious consequences on the economy, society and environment are a crucial issue in the beginning of this century. In order to meet the growing demand for energy in a sustainable way, minimizing the emission of pollutants and causing the least possible impact to the environment, there is a growing motivation to develop technologies based on renewable energy sources that can replace partially the use of fossil fuels.

The feasibility of the development in this area depends on the abundance of natural resources. Renewable energies are considered an important resource in many countries around the world and biomass and its derivatives are the most common form of such energy. Thus, biodiesel produced from vegetable oils and animal fats is a potentially renewable substitute for diesel oil [1-4].

Biodiesel is a renewable and biodegradable fuel to be used in internal combustion engines with compression ignition. The ASTM (American Society for Testing and Materials) defines it as monoalkyl esters of fatty acids, derived from a renewable lipid feedstock, such as vegetable oil or animal fat [5]. These fatty acids esters have physicochemical properties similar to mineral diesel specifications and therefore can replace partially or completely the petroleum-based diesel. The use of biodiesel in diesel engines, as a pure fuel or blended in any proportion to fossil diesel, can be made without needing any change in the engine, while keeping its durability and reliability [6-8].

\footnotetext{
* Corresponding author. Tel.: + 5571 32839808; fax: + 557132839801 E-mail address: ctalves@ufba.br (C.T. Alves).
}

This biofuel is produced by the transesterification reaction of a vegetable oil or animal fat with a short chain alcohol, under supercritical conditions or in the presence of a catalyst, like enzymes or chemical compounds, of alkali or acid nature, generating glycerol as co-product $[1,7]$. In principle, any type of feedstock containing free fatty acids or triglycerides, such as vegetable oils and animal fats, can be converted into biodiesel. However, the final products must meet stringent quality requirements before being accepted as biodiesel. A generic transesterification reaction can be produced in presence of a suitable acid or basic catalyst using any type of vegetable oils and fats with short chain alcohols.

WFO is often discarded into rivers and springs leading to environmental impacts that could be avoided by the environmentally friendly production of biodiesel from WFO [9-11]. Another aspect that should be considered is the increasing cost of virgin vegetable oils in the recent years, because the cost of feedstock is approximately $70-95 \%$ of the total operating costs in a biodiesel commercial plant. As compared to refined vegetable oils, the cost of WFO ranges from $60 \%$ to free, depending on the source, availability and quantity [12-14].

The transesterification reaction can be performed using various types of catalysts, such as acid (sulfuric, sulfonic, phosphoric and hydrochloric acids), or basic (potassium and sodium hydroxides, metal alkoxides or hydrotalcites), but heterogeneous catalysts are now preferred in order to avoid neutralization and separation steps [15-24].

Zinc aluminate $\left(\mathrm{ZnAl}_{2} \mathrm{O}_{4}\right)$ is an oxide with a normal spinel $\mathrm{AB}_{2} \mathrm{O}_{4}$ structure and is commonly used as a catalyst or support in many catalytic reactions such as cracking, dehydrogenation, acetylation and transesterification $[21,22,25,26]$. Zinc aluminate consists of an arrangement of closed packing $c f c$ atoms $F d 3 m$, presenting tetrahedral interstices, $\mathrm{A}$, and octrahedral interstices, $\mathrm{B}$, occupied by the bivalent 
and trivalent ions respectively [26]. Powders with nanosized particles of zinc aluminate may be prepared by several methods, including hydrothermal synthesis, coprecipitation and the sol-gel techniques [27-31].

The synthesis of nanosized powders by combustion reaction is a promising technique for the preparation of $\mathrm{ZnAl}_{2} \mathrm{O}_{4}$. This method is simple and is based on a very fast and exothermic chemical reaction to form the material. The key feature of the process is that the necessary heat to govern the reaction is supplied by the reaction itself and, therefore, the combustion method is self-sustaining after the beginning of the reaction. Another important feature is that the combustion reaction reaches temperatures high enough to achieve the formation of powders in a short time, with the release of a great amount of gases. This method does not include many steps and produces a high purity and chemically homogeneous powders often consisting of nanosized particles [32,33].

The present work aimed to produce biodiesel using WFO, ethanol or methanol as starting materials, in the presence of a $\mathrm{ZnAl}_{2} \mathrm{O}_{4}$ catalyst prepared by the combustion reaction method. The experiments were conducted in a batch reactor and the influence of the reaction parameters, temperature, alcohol:WFO molar ratio, catalyst ratio and catalyst reuse, were investigated in this study.

\section{Experimental}

\subsection{Materials and equipment}

The raw material, waste frying oil (WFO), was received from commercial establishments such as restaurants, hospitals and others in the Salvador city, Brazil. Before being fed to the reactor for biodiesel production, WFO was pre-treated to remove undesirable impurities for the transesterification reaction, such as suspended particulate materials, water and free fatty acids.

Analytical grade reagents were used: anhydrous ethanol (99.9\% of purity) and methanol (99.9\% of purity) were purchased from Synth ${ }^{\circledR}$, and were used as the limiting reactant in the transesterification reaction. Ethanol and methanol were used in excess relative to stoichiometric conditions of the reaction, because the transesterification reaction is reversible. The experiments were performed in a Parr stainless steel batch reactor of $1000 \mathrm{~mL}$ capacity, equipped with temperature, internal pressure and stirring controllers.

\subsection{Pre-treatment of WFO}

The as-received WFO was filtered to remove the suspended particulate matter, neutralized with potassium hydroxide and water to decrease the acidity and to remove remaining impurities that usually are solids residues and finally the oil was dried at $120{ }^{\circ} \mathrm{C}$ to eliminate the excess water. The volume of oil recovered after pretreatment was $\sim 85 \%$.

The fatty acid composition of the pre-treated WFO was determined by gas chromatography (GC-3800A Varian) and the results are shown in Table 1.

Table 1

Fatty acid composition of the waste frying oil (WFO).

\begin{tabular}{|c|c|c|c|}
\hline Fatty acid & Nomenclature & wt.\% & \\
\hline & & Sample 01 & Sample 02 \\
\hline C16:0 & Palmtic acid & 11.33 & 11.48 \\
\hline C18:0 & Estearic acid & 3.53 & 3.53 \\
\hline 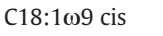 & Oleic acid & 22.71 & 21.73 \\
\hline C18:1 $\omega 9$ trans & Elaidic acid & 1.49 & 1.43 \\
\hline $\mathrm{C} 18: 2 \omega 6 \mathrm{cis}$ & Linoleic acid & 54.82 & 55.67 \\
\hline $\mathrm{C} 18: 2 \omega 6$ trans & Linolelaidic acid & 0.18 & 0.16 \\
\hline $\mathrm{C} 18: 3 \omega 3$ & Linolenic acid & 5.62 & 6 \\
\hline C20:0 & Eicosanoic acid & 0.32 & 0 \\
\hline
\end{tabular}

\subsection{Catalyst preparation and characterization}

Zinc aluminate was synthesized by the combustion reaction method using p.a. grade reagents, namely aluminum and zinc nitrates, as starting materials and urea, as fuel. The amounts of the metal nitrates and urea were calculated on the basis of the stoichiometry of the total oxidizing and reducing valences of the reagents, as indicated in the literature, which serve as the numerical coefficients for the stoichiometric balance so that the energy released is maximum $[32,33]$. The batches were placed in a vitreous silica basin, homogenized and directly heated up in the furnace to temperature around $400{ }^{\circ} \mathrm{C}$ until the ignition took place, producing the zinc aluminate in a foam form. The thus obtained material was heated at $500{ }^{\circ} \mathrm{C}$ for further 20 minutes in order to eliminate any volatile product and then sieved in the range of $0.149-0.105 \mathrm{~mm}$.

The obtained powder was characterized by X-ray diffraction (Shimadzu 6000 diffractometer, Cuk $\alpha$ with a Ni filter and scanning rate of $2^{\circ} 2 \theta \mathrm{min}^{-1}$, in a $2 \theta$ range of $20-60^{\circ}$ ). BET specific surface area and the pore volume of the catalysts were determined from $\mathrm{N}_{2}$ adsorption isotherms collected in a Micromeritics ASAP 2020 system and $\mathrm{NH}_{3}$-TPD and TPD- $\mathrm{CO}_{2}$ (temperature programmed desorption of ammonia or carbon dioxide) profiles were collected in the temperature range of $20-800{ }^{\circ} \mathrm{C}$, at a heating rate of $10^{\circ} \mathrm{C} \mathrm{min}-1$, using a Micromeritics 2720 system. FTIR spectra were collected using a Perkin Elmer Spectrum BX spectrometer and TGA analyses were carried out in a Shimadzu H-50 system.

\subsection{Transesterification reaction}

A $316 \mathrm{~L}$ stainless steel batch reactor of $1000 \mathrm{~mL}$ capacity was used for the transesterification reaction. The reaction runs were carried out for 2 hours, using alcohol:oil molar ratio of $40: 1$, temperature range of $60-200{ }^{\circ} \mathrm{C}$, catalyst:oil ratio of $1-10 \%$ wt., under $700 \mathrm{rpm}$ stirring, provided by the Parr reactor system. The oil, alcohol and catalyst were weighted, introduced into the reactor, and allowed to rest until the reaction temperature was reached and the system was stirred. At the end of reaction time (2 hours), the reactor was cooled down and the samples were withdrawn at room temperature. The insoluble catalyst was recovered by filtration, vacuum dried in an oven at $50{ }^{\circ} \mathrm{C}$, sieved and reused in subsequent reaction cycles. The reaction mixture was introduced into a separation funnel where the glycerin was decanted, and then the excess alcohol was recovered using a rotary evaporator. The biodiesel samples were characterized as follows.

\subsection{Biodiesel characterization}

The yield of ethyl and methyl esters was determined by a gas chromatographic procedure. The biodiesel aliquots were diluted with n-heptane and the obtained solutions were analyzed by GC (CP 3800A Varian Chrompack) according to DIN EN14105 [34], with a $30 \mathrm{~m}$ long capillary column, Ultimetal VF $5 \mathrm{HT}(30 \mathrm{~m} \times 0.32 \mathrm{~mm} \times 0.10 \mu \mathrm{m}), \mathrm{He}$ $\left(3 \mathrm{~mL} \mathrm{~min}{ }^{-1}\right)$ as carrier gas, and a flame ionization detector. The column temperature program was as follows: the initial temperature was $50{ }^{\circ} \mathrm{C}$, the first rate was $15^{\circ} \mathrm{C} \mathrm{min}-1$ up to $180{ }^{\circ} \mathrm{C}$, the second rate was $7{ }^{\circ} \mathrm{C} \mathrm{min}{ }^{-1}$ up to $230{ }^{\circ} \mathrm{C}$ and the third rate was $30{ }^{\circ} \mathrm{C} \mathrm{min}{ }^{-1}$ up to $380^{\circ} \mathrm{C}$ with holding time of 10 minutes.

\section{Results and discussion}

\subsection{Preparation and characterization of $\mathrm{ZnAl}_{2} \mathrm{O}_{4}$}

The overall reaction that represents the synthesis of the $\mathrm{ZnAl}_{2} \mathrm{O}_{4}$ catalysts is given by the self-combustion method [32].

The TGA analysis of the product of the combustion reaction indicated that no residual carbon deposit remained in the porous 
structure of the $\mathrm{ZnAl}_{2} \mathrm{O}_{4}$ powder, suggesting that the reaction was complete.

The X-ray diffraction (XRD) patterns collected for the zinc aluminate powder correspond to the characteristic peaks of the cubic spinel-phase $\mathrm{ZnAl}_{2} \mathrm{O}_{4}$, namely, the peaks at 31.3, 36.9, 44.9, 55.6, $59.4,65.2,74.1$ and $77.3^{\circ} 2 \theta$ [26]. These XRD patterns are in accordance with the JCPDS card (JCPDS No. 05-0669) and also indicate that the product is a single-phase and high purity material. This is a feature of the combustion reaction for the synthesis of oxide powders. Better crystallization of the oxide powders is attained when high temperatures are reached during the combustion reaction.

The specific surface area of the as prepared powder was determined to be $15 \mathrm{~m}^{2} \mathrm{~g}^{-1}$ and the pore volume $0.023 \mathrm{~cm}^{3} \mathrm{~g}^{-1}$. The surface area and porosity of zinc aluminate are strongly affected by the preparation method and by the calcination temperature. High surface area has been reported for samples prepared by sol-gel or hydrothermal methods but lower surface area may be expected for zinc aluminate prepared by combustion reaction as consequence of the very high temperatures attained during the combustion synthesis [32]. The $\mathrm{N}_{2}$ physisorption isotherms and the $\mathrm{BJH}$ pore size distribution in the $\mathrm{ZnAl}_{2} \mathrm{O}_{4}$ powder are shown in Fig. 1. Isotherms of type IV and hysteresis loop of type $\mathrm{H}_{2}$ are usually assigned to mesoporous materials with a complex structure where network effects are important. The bimodal pore size distribution also confirmed a low contribution of micropores [26,27].

The zinc aluminate spinel is usually considered to be a neutral solid but the presence of a typical Lewis acid sites (from high temperatures obtained from the combustion reaction indicating a very low quantity of water) of different strengths and the distribution of surface acidity have been reported and seem to depend on the preparation method and treatment of the sample $[28,35]$.

In order to assess the balance of surface acidity and basicity on the zinc aluminate spinel prepared by combustion reaction, the number and distribution of the surface acid and base sites on the sample were determined by $\mathrm{NH}_{3}$-TPD and $\mathrm{CO}_{2}$-TPD, as respectively shown in Fig. 2. The desorption profiles of $\mathrm{NH}_{3}$ and $\mathrm{CO}_{2}$ correspond to the overlap of desorption peaks from sites of different types and strength, clearly confirming the presence of both acid and base surface sites on the sample. Quantitative analyses of the TPD profiles indicated that the total acidity was $370 \mu \mathrm{mol} \mathrm{g}^{-1}$ and the total basicity was $258 \mu \mathrm{mol} \mathrm{g}^{-1}$. In both cases, the low temperature peak $\left(<200{ }^{\circ} \mathrm{C}\right)$ was assigned to the contribution of physisorption and corresponded to $<1 \%$ of both acid and base sites. On the other hand, the strong sites $\left(>400{ }^{\circ} \mathrm{C}\right.$ ) corresponded to nearly $75 \%$ of both acid and base

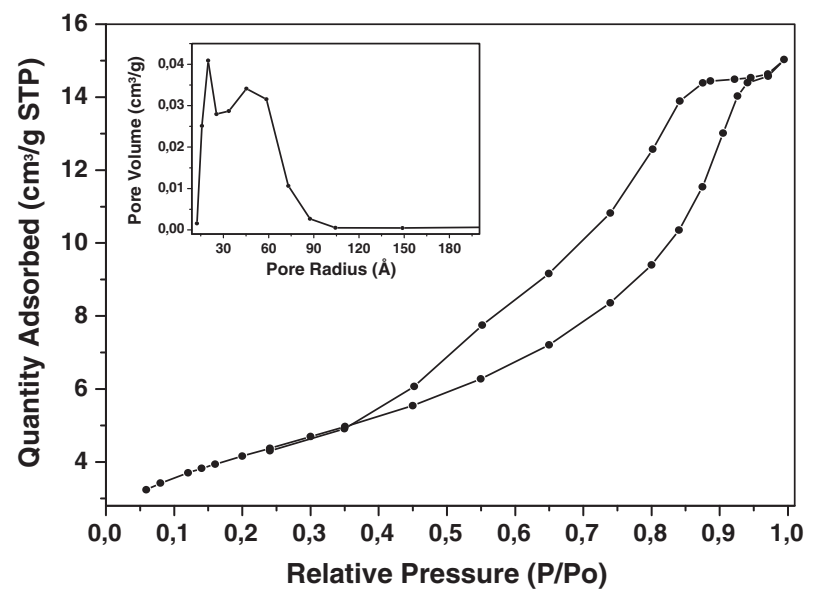

Fig. 1. $\mathrm{N}_{2}$ physisorption isotherms and the $\mathrm{BJH}$ pore size distribution in the $\mathrm{ZnAl}_{2} \mathrm{O}_{4}$ powder.
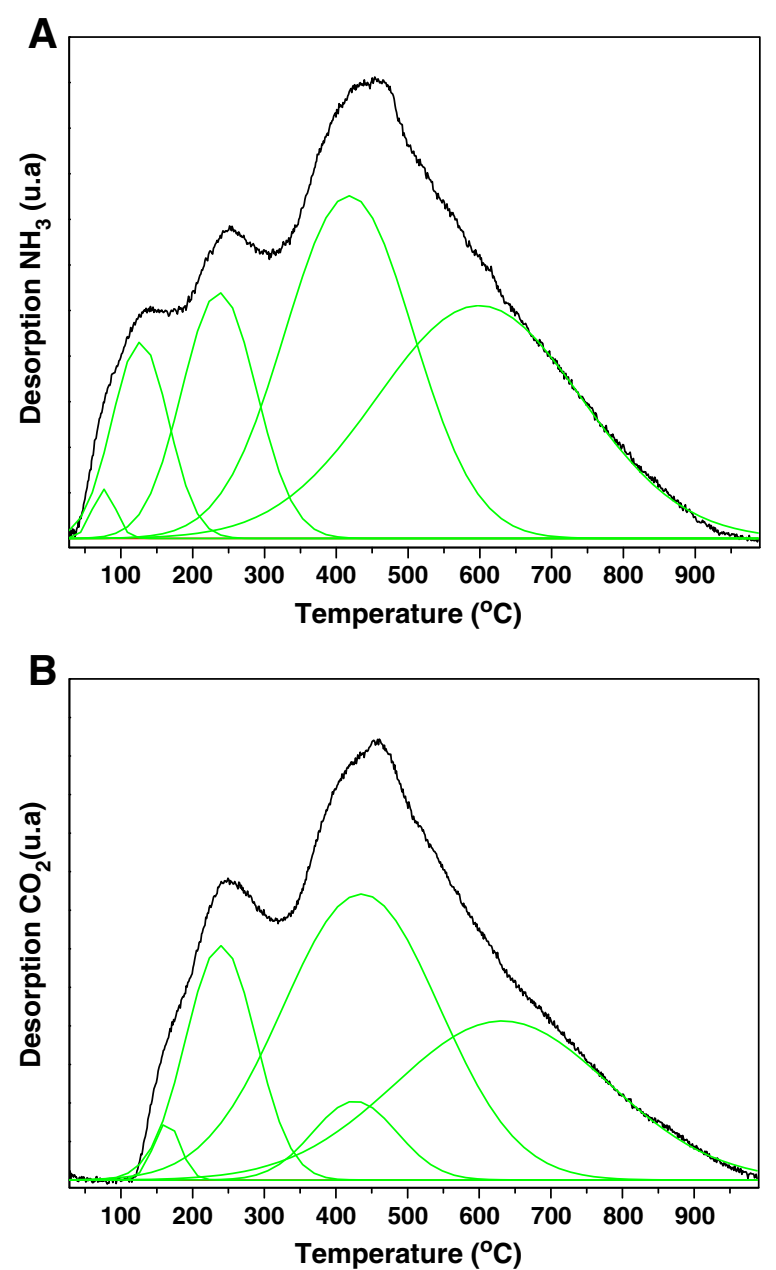

Fig. 2. $\mathrm{NH}_{3}$-TPD (A) and $\mathrm{CO}_{2}$-TPD (B) of $\mathrm{ZnAl}_{2} \mathrm{O}_{4}$ spinel catalyst prepared by combustion reaction.

sites. These findings indicate that the acidity of the sample prepared by combustion reaction is somewhat lower than that of $\gamma$-alumina in opposition to zinc aluminate spinel prepared by hydrothermal methods [28]. Thus, in spite of the acid character indicated by the balance of acid and base sites, the catalyst used in this study showed similar amounts of strong acid and base sites and this feature may be useful for the transesterification of WFO, a mixture of triglycerides with very low acid values.

\subsection{Transesterification reaction experiments}

\subsubsection{Influence of the reaction temperature and catalyst:oil ratio}

In order to investigate the influence of the temperature on the transesterification of WFO with ethanol and methanol, 2 hours reaction runs were carried out, in duplicate, in the range of $60-200{ }^{\circ} \mathrm{C}$, for different catalyst:oil ratio (1-10 wt.\% of the initial amount of oil), alcohol:oil molar ratio $=40: 1$, under stirring $(700 \mathrm{rpm})$. The yields of ethyl and methyl esters were plotted as a function of the reaction temperature and are shown in Fig. 3. The ester yields are high at temperatures higher than $100{ }^{\circ} \mathrm{C}$. The highest yields were attained using $10 \mathrm{wt} . \%$, over the temperature range for both ethanol and methanol but, in general, the influence of the catalyst ratio is more significant at lower reaction temperatures. In general, the yields increased with the increase of temperature and catalyst ratio. In fact, high methyl ester yields have been previously reported in the 

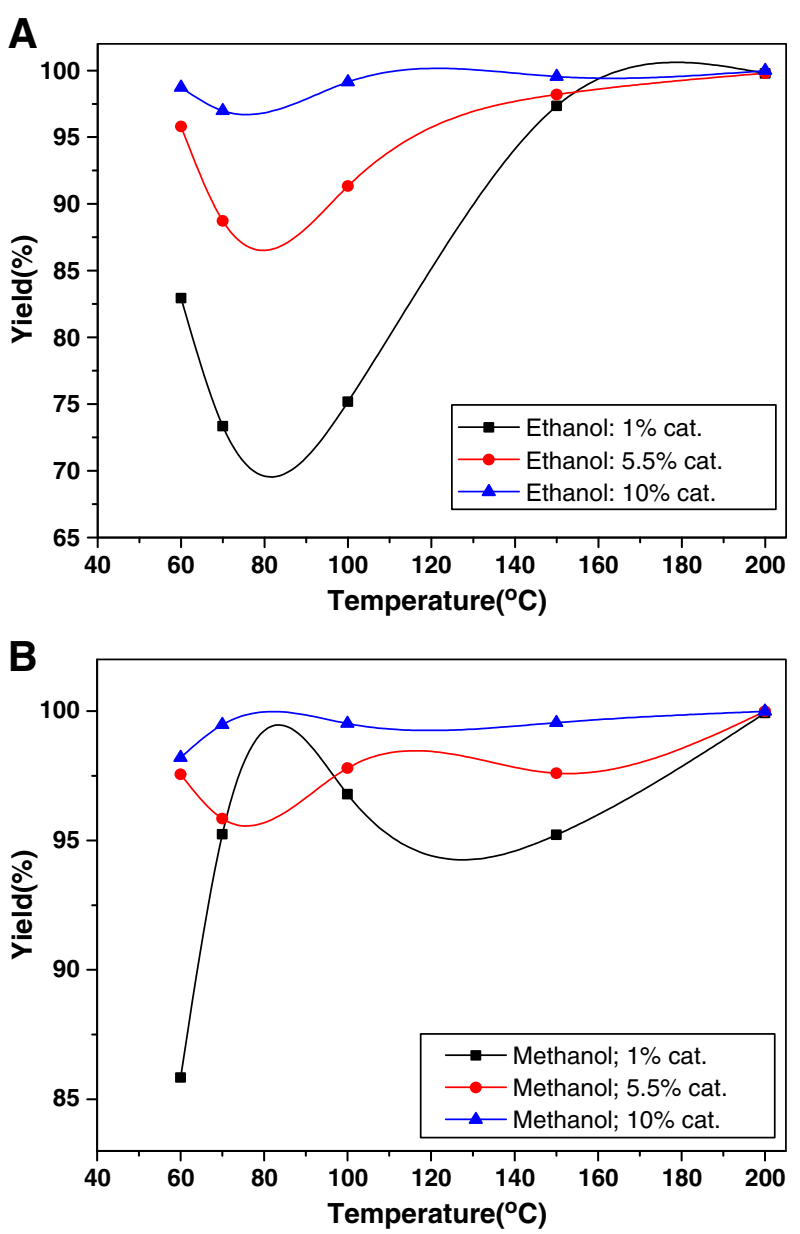

Fig. 3. Influence of temperature and catalyst dosage on the transesterification of WFO with ethanol (A) and methanol (B). $T=200{ }^{\circ} \mathrm{C}$, alcohol:WFO molar ratio $=40: 1$.

transesterification of rapeseed oil with methanol, at $200{ }^{\circ} \mathrm{C}$, using 12.5 wt.\% $\mathrm{ZnAl}_{2} \mathrm{O}_{4}$ :oil and 27:1 methanol:oil ratio [21].

\subsubsection{Influence of the alcohol:WFO molar ratio}

In spite of the stoichiometric alcohol:oil molar ratio in the transesterification reaction, an excess of alcohol is generally used to shift the reaction equilibrium towards the products in order to achieve high yield of esters and to enhance solubility of the alcohol in the oil. One of the most important variables affecting the yield of ester is the molar ratio of alcohol to oil employed.

The overall process of transesterification reaction is a sequence of three consecutive and reversible reactions, in which diglycerides and monoglycerides are formed as intermediates. The stoichiometric reaction requires 1 mole of a triglyceride and 3 moles of alcohol to obtain 3 moles of fatty alkyl ester and 1 mole of glycerol. However, when the molar ratio of alcohol to oil is increased, the reverse reaction is negligible, because the glycerol formed is not miscible in the ester formed, leading two phases system. The frequency of the collisions between the product molecules is considerably reduced, preventing the reverse reaction. Most of the researches have used higher molar ratios, up to $45: 1$, particularly when the triglyceride contained large amounts of free fatty acids [4,36-39].

Pugnet et al. [21] reported that high yields could be obtained using molar methanol:rapeseed oil molar ratio $=27$, at $200{ }^{\circ} \mathrm{C}$, in the presence of $\mathrm{ZnO}$ based heterogeneous catalysts. The influence of the alcohol:oil molar ratio was investigated in the range of alcohol:WFO $=6-65$, at $200{ }^{\circ} \mathrm{C}$. The results are collected in Fig. 4 and indicate that the ratio

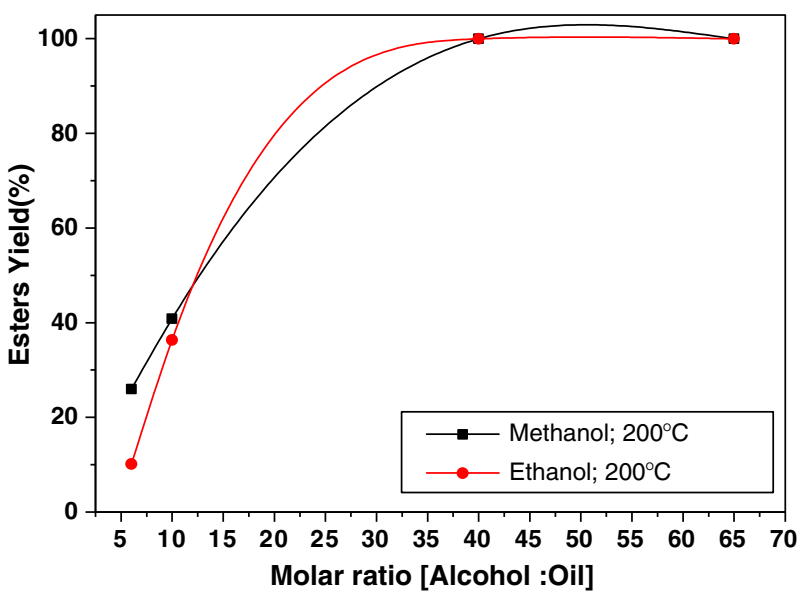

Fig. 4. Influence of the alcohol:WFO molar ratio, at $200{ }^{\circ} \mathrm{C}$, using $10 \% \mathrm{ZnAl}_{2} \mathrm{O}_{4}$.

alcohol:WFO $=40: 1$ is the more adequate for the transesterification of WFO, either with methanol or ethanol.

\subsubsection{Catalyst reuse}

The reuse of catalyst is an important issue for the industrial applications. Fig. 5 shows the FTIR spectra of fresh and reused $\mathrm{ZnAl}_{2} \mathrm{O}_{4}$ catalyst. The spectrum collected for the fresh powder obtained by combustion reaction showed two strong bands around 670 and $560 \mathrm{~cm}^{-1}$, assigned to $\mathrm{Al}-\mathrm{O}$ stretching and $\mathrm{O}-\mathrm{Al}-\mathrm{O}$ bending vibrations of $\mathrm{AlO}_{6}$ groups in the spinel structure, and two bands between 450 and $700 \mathrm{~cm}^{-1}$, assigned to the vibrations modes of octahedral and tetrahedral groups $[26,40]$.

In the present study, $\mathrm{ZnAl}_{2} \mathrm{O}_{4}$ was recovered from the reaction mixture by vacuum filtration and dried in a vacuum oven at $50{ }^{\circ} \mathrm{C}$, without use of any solvent to extract adsorbed organic matter from the catalyst before reuse. Thus, bands assigned to the main products of the transesterification reaction could be observed along with those of the catalyst and they increased after each reaction cycle. A strong band between 3600 and $3200 \mathrm{~cm}^{-1}$, assigned to the $\mathrm{OH}$ stretching; two bands between 3000 and $2850 \mathrm{~cm}^{-1}$, assigned to alkane groups; two bands at 1465 and $1375 \mathrm{~cm}^{-1}$, assigned to $\mathrm{CH}_{3}$ and $\mathrm{CH}_{2}$, indicate the presence of glycerol in the recovered catalysts [40]. On the other hand, the bands between 1750 and $1730 \mathrm{~cm}^{-1}$ and 1300 and $1000 \mathrm{~cm}^{-1}$, respectively corresponding to $\mathrm{CO}$ and $\mathrm{C}-\mathrm{O}$ stretching modes, suggest presence of ester groups in the porous

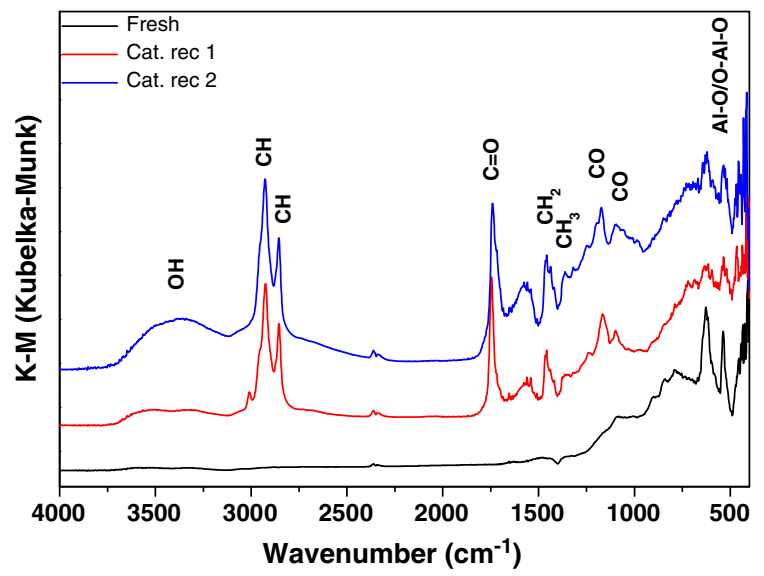

Fig. 5. FTIR spectra of $\mathrm{ZnAl}_{2} \mathrm{O}_{4}$ catalyst: fresh, and recovered after the 1 st and 2 nd reaction cycles. 
catalyst. In addition, vibration modes assigned to carboxylic acids $(\mathrm{RCOOH})$ suggest that the WFO starting material was not completely converted to ester.

Fig. 6 shows the DRX patterns of the fresh and recovered catalysts (after the first and second reaction cycles). No significant change could be noticed, suggesting that the spinel structure of the $\mathrm{ZnAl}_{2} \mathrm{O}_{4}$ catalyst was stable either under the reaction conditions or after the first and second recovery treatment.

The reuse of the $\mathrm{ZnAl}_{2} \mathrm{O}_{4}$ catalyst was investigated in 3 reaction cycles of WFO transesterification with methanol and ethanol, at 100, 150 and $200{ }^{\circ} \mathrm{C}$, for different catalyst ratio. The results are presented in Figs. 7 and 8, respectively. At low temperatures, the yields of esters were low probably because of the difference in the miscibility between alcohol and oil, mainly for ethanol, which has a longer chain. Between $60{ }^{\circ} \mathrm{C}$ and $70{ }^{\circ} \mathrm{C}$ may have been occurred the formation of four phases as oil, liquid alcohol, gaseous alcohol and catalyst, which hinders the mass transfer in catalyst pores, decreasing the esters formation. For high temperatures, namely above boiling point of alcohol, the miscibility factor becomes less significant due to the better miscibility of gaseous alcohol and oil.

In general, lower yields were obtained in the third reaction cycle and the decrease was more significant at $100{ }^{\circ} \mathrm{C}$, using both alcohols and over the investigated range of catalyst ratio. These facts may be due either to a thermal effect or to the mass loss during the procedure to recover the catalyst. At higher temperatures, desorption of products from the catalyst surface is favored and the lower viscosity of WFO contributes to reduce mass transfer limitations. Leaching of zinc from zinc aluminate catalysts prepared by solid state reaction, impregnation and coprecipitation has been reported [21,22,25,26]. In spite of this, no zinc depletion could be determined by EDX analyses of the catalysts after 3 reaction cycles and no significant homogeneous reaction was observed in a side test, even after the first reaction run. Thus, it seems reasonable that some of the fine catalyst powder obtained by the combustion reaction method could be retained in the products or in the glycerol. Then, the use of larger catalyst particles may be envisaged to overcome this issue, allowing to high yields in a higher number of reaction cycles.

\section{Conclusion}

Methyl and ethyl esters have been successfully produced by the transesterification of waste frying oil (WFO), using a $\mathrm{ZnAl}_{2} \mathrm{O}_{4}$ catalyst prepared by the combustion reaction method. A single-phase and high purity spinel material was obtained, showing a bimodal pore

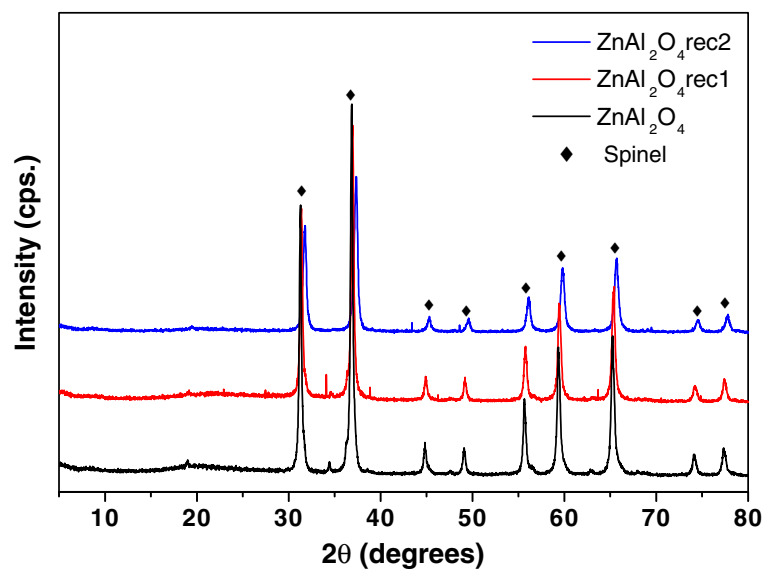

Fig. 6. $\mathrm{X}$ ray diffractograms of $\mathrm{ZnAl}_{2} \mathrm{O}_{4}$ catalyst: fresh and recovered after the 1 st and 2nd reaction cycles.
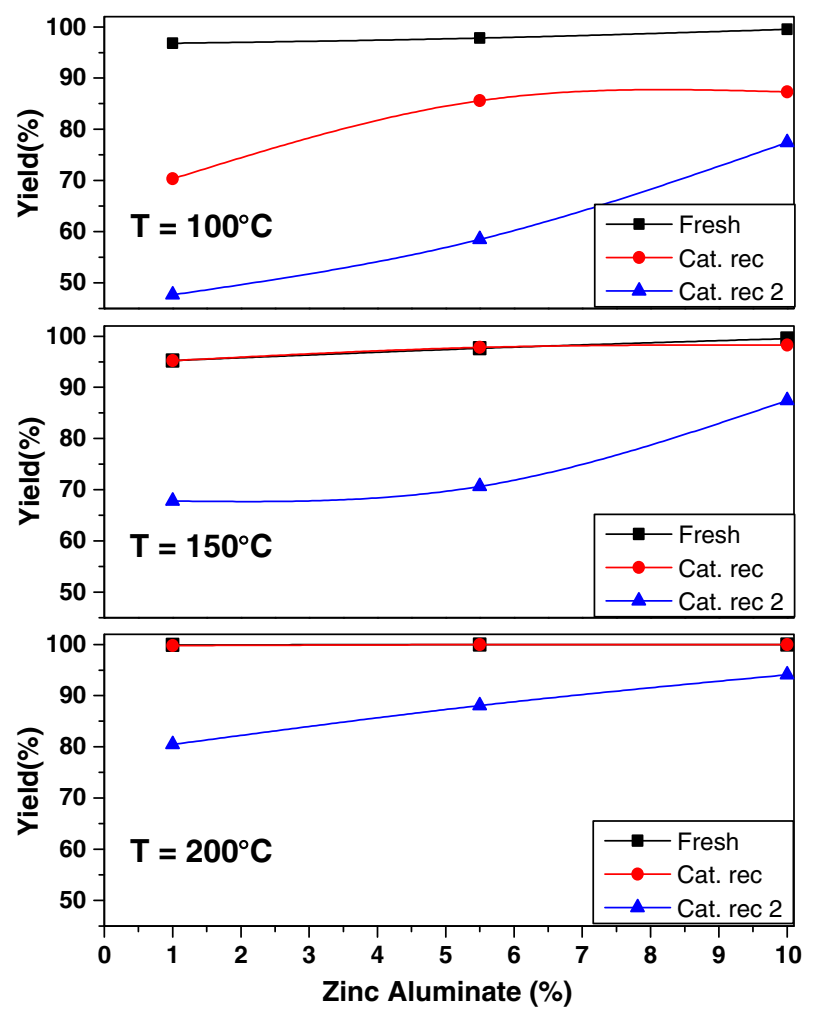

Fig. 7. Methyl ester yields at 100,150 and $200{ }^{\circ} \mathrm{C}$, methanol:WFO molar ratio $=40: 1$, $1-10 \% \mathrm{ZnAl}_{2} \mathrm{O}_{4}$ catalyst: fresh and recovered after the 1 st and 2 nd reaction cycles.

size distribution. In spite of the acid character indicated by the balance of acid and base sites, similar amounts of strong acid and base sites were determined on the catalyst surface. High ester yields $(>95 \%)$ were obtained using alcohol:WFO molar ratio $=40$, at $T>150{ }^{\circ} \mathrm{C}$, using $1-10 \%$ catalyst:WFO ratio. The catalyst was
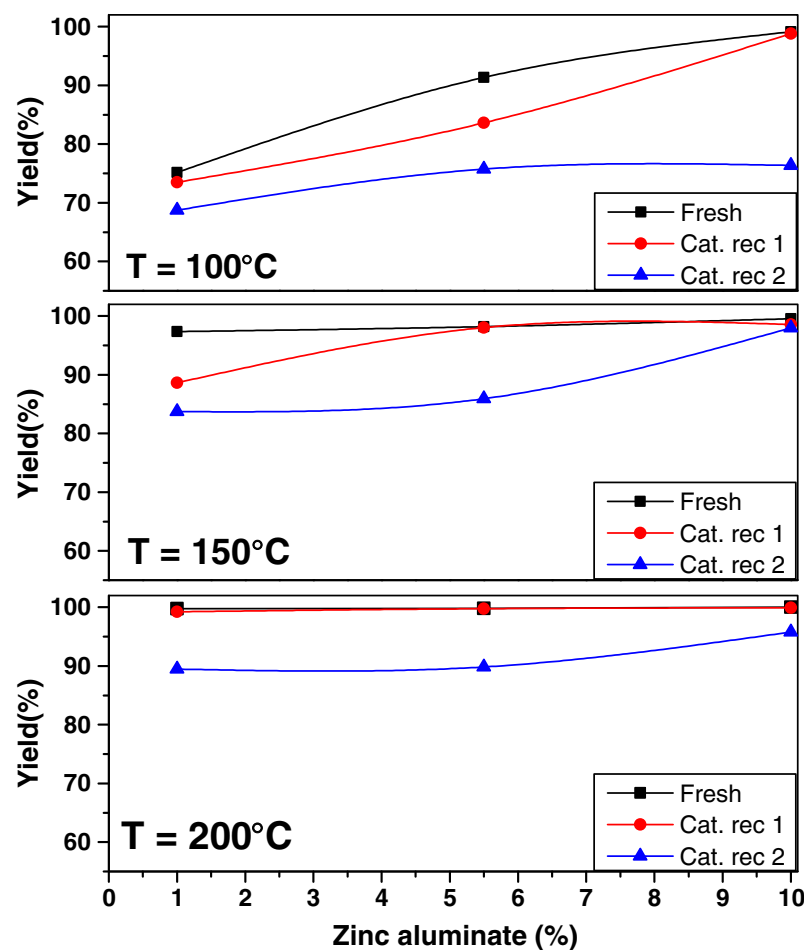

Fig. 8. Ethyl ester yields at 100,150 and $200{ }^{\circ} \mathrm{C}$, ethanol:WFO molar ratio $=40: 1,1$ $10 \% \mathrm{ZnAl}_{2} \mathrm{O}_{4}$ catalyst: fresh and recovered after the 1 st and 2 nd reaction cycles. 
recovered and used in 3 reaction cycles but either the increase of carbon deposits or loss of fine catalyst particles during the recovery steps could account for the yield decrease after the third reaction cycle. Finally, the results presented herein demonstrate that the transesterification of waste frying oil (WFO) with ethanol, in the presence of the $\mathrm{ZnAl}_{2} \mathrm{O}_{4}$ heterogeneous catalyst, is a sustainable alternative to produce biodiesel, using renewable and waste raw materials.

\section{Acknowledgments}

This work was supported by CNPq-Conselho Nacional de Desenvolvimento Científico e Tecnológico, of the Ministry for Science and Technology of Brazil.

\section{References}

[1] V.K.S. Araujo, S. Hamacher, L.F. Scavarda, Economic assessment of biodiesel production from waste frying oils, Bioresource Technology 101 (2010) 4415-4422.

[2] B. Freedman, E.H. Pryde, T.L. Mounts, Variables affecting the yields of fatty esters from transesterified vegetable oils, Journal of the American Oil Chemists' Society 61 (1984) 1638-1643.

[3] D. Cantrell, L. Gillie, K. Wilson, A. Lee, Structure-reactivity correlations in MgA hydrotalcite catalysts for biodiesel synthesis, Applied Catalysis A: Environmenta 287 (2005) 183-190.

[4] D.R. Mendonça, H.M.C. Andrade, P.R.B. Guimarães, R.F. Vianna, S.M.P. Meneghetti, L.A.M. Pontes, L.S.G. Teixeira, Application of full factorial design and Doehlert matrix for the optimisation of beef tallow methanolysis via homogeneous catalysis, Fuel Processing Technology 92 (2011) 342-348.

[5] J.M. Marchetti, V.U. Miguel, A.F. Errazu, Techno-economic study of different alternatives for biodiesel production, Fuel Processing Technology 89 (2008) 740-748

[6] M.J. Dabdoub, J.L. Bronzel, M.A. Rampin, Biodiesel: a critical overview on the current status and perspectives at the academy and industry, Quimica Nova 32 (2009) 776-792.

[7] J. Janaun, N. Ellis, Perspectives on biodiesel as a sustainable fuel, Renewable and Sustainable Energy Reviews 14 (2010) 1312-1320.

[8] J.V. Gerpen, Biodiesel processing and production, Fuel Processing Technology 86 (2005) 1097-1107.

[9] A.B. Chhetri, K.C. Watts, M.R. Islam, Waste cooking oil as an alternate feedstock for biodiesel production, Energies 1 (2008) 3-18.

[10] M. Mittelbach, P. Tritthart, Diesel fuel derived from vegetable oils, III. Emission tests using methil esters of used frying oil, Journal of the American Oil Chemists Society 65 (1988) 1185-1187.

[11] M.J. Nye, T.W. Williamson, W. Deshpande, J.H. Schrader, W.H. Snively, Conversion of used frying oil to diesel fuel by transesterification: Preliminary tests, Journal of the American Oil Chemists' Society 60 (1983) 1598-1601.

[12] D.Y.C. Leung, Y. Guo, Transesterification of neat and used frying oil: optimization for biodiesel production, Fuel Processing Technology 87 (2006) 883-890.

13] Z.J. Predojevic, The production of biodiesel from waste frying oils: a comparison of different purification steps, Fuel 87 (2008) 3522-3528.

[14] E. Moretto, R. Fett, Tecnologia de óleos e gorduras vegetais na indústria de alimentos, Livraria Varela, São Paulo, 1998.

[15] Y.C. Sharma, B. Singh, J. Korstad, Advancements in solid acid catalysts fo ecofriendly and economically viable synthesis of biodiesel, Biofuels, Bioproducts and Biorefining 5 (2011) 69-92.

[16] B. Freedman, R.O. Butterfield, E.H. Pryde, Transesterification kinetics of soybean oil, Journal of the American Oil Chemists' Society 63 (1986) 1375-1380.

[17] J. Schmidt, D. Reusch, K. Elgeti, R. Schomacker, Kinetik der Umesterung von Ethanol und Butylacetat-Ein Modellsystem für die Reaktivrektifikation, Chemie Ingenieur Technik 71 (1999) 704-708.

[18] S. Gryglewicz, Alkaline-earth metal compounds as alcoholysis catalysis for ester oils synthesis, Applied Catalysis A: General 192 (2000) 23-28.
[19] Y.C. Sharma, B. Singh, J. Korstad, Application of an efficient nonconventional heterogeneous catalyst for biodiesel synthesis from Pongamia pinnata oil, Energy \& Fuels 24 (2010) 3223-3231.

[20] K.G. Georgogianni, A.K. Katsoulidis, P.J. Pomonis, G. Manos, M.G. Kontominas, Transesterification of rapeseed oil for the production of biodiesel using homogeneous and heterogeneous catalysis, Fuel Processing Technology 90 (2009) 1016-1022.

[21] V. Pugnet, S. Maury, V. Coupard, A. Dandeu, Anne-Agathe Quoineaud, Jean-Louis D.T. Bonneau, Stability, activity and selectivity study of a zinc aluminate heterogeneous catalyst for the transesterification of vegetable oil in batch reactor, Applied Catalysis A: General 374 (2010) 71-78.

[22] Z. Helwani, M.R. Othman, N. Aziz, W.J.N. Fernando, J. Kim, Technology for production of biodiesel focusing on green catalytic techniques: a review, Fuel Processing Technology 90 (2009) 1502-1515.

[23] Y.C. Sharma, B. Singh, J. Korstad, Latest developments on application of heterogenous basic catalysts for an efficient and eco friendly synthesis of biodiesel: a review, Fuel 90 (2011) 1309-1324.

[24] M. Zabeti, W.M.A.W. Daud, M.K. Aroura, Activity of solid catalysts for biodiesel production: a review, Fuel Processing Technology 90 (2009) 770-777.

[25] M. Kim, S. Yan, S.O. Salley, K.Y.S. Ng, The effect of sodium on the catalytic activity of $\mathrm{ZnO}-\mathrm{Al}_{2} \mathrm{O}_{3} / \mathrm{ZSM}-5$ and $\mathrm{SnO}-\mathrm{Al}_{2} \mathrm{O}_{3} / \mathrm{ZSM}-5$ for the transesterification of vegetal oil with methanol, Catalysis Communications 10 (2009) 1913-1919.

[26] S. Farhadi, S. Panahandehjoo, Spinel-type zinc aluminate $\left(\mathrm{ZnAl}_{2} \mathrm{O}_{4}\right)$ nanoparticles prepared by the co-precipitation method: a novel green and recyclable heterogeneous catalyst for the acetylation of amines, alcohols and phenols under solvent free conditions, Applied Catalysis A: General 382 (2010) 293-302.

[27] G. Aguilar-Rios, M. Valenzuela, P. Salas, H. Armendariz, P. Bosch, G. Del Toro, R. Silva, V. Bertin, S. Castillo, A. Ramirez-Solis, I. Schifter, Hydrogen interactions and catalytic properties of platinum-tin supported on zinc aluminate, Applied Catalysis A: General 127 (1995) 65-75.

[28] J. Wrzyszcz, M. Zawadzki, J. Trawczy'nski, H. Grabowska, W. Mi'sta, Some catalytic properties of hydrothermally synthesised zinc aluminate spinel, Applied Catalysis A: General 210 (2001) 263-269.

[29] M. Zawadzki, J. Wrzyszcz, Hydrothermal synthesis of nanoporous zinc aluminate with high surface area, Materials Research Bulletin 35 (2000) 109-114.

[30] A.R. Phani, M. Passacantando, S. Santucci, Synthesis and characterization of zinc aluminum oxide thin films by sol-gel technique, Materials Chemistry and Physics 68 (2001) 66-71.

[31] M.A. Valenzuela, G. Aguilar, P. Bosh, H. Armendariz, P. Salas, A. Montoya, Effect of calcium addition on zinc aluminate spinel, Catalysis Letters 15 (1992) 179-188.

[32] K.C. Patil, M.S. Hedge, T. Rattan, S.T. Aruna, Chemistry of nanocrystalline oxide materials, Combustion synthesis, properties and applications, Word Scientific Pub, 2008.

[33] A.C.F.M. Costa, R.T. Lula, R.H.G.A. Kiminami, L.V.F. Gama, A.A. de Jesus, H.M.C. Andrade, Preparation of nanostrutured $\mathrm{NiFe}_{2} \mathrm{O}_{4}$ by comustion reaction, Journal of Materials Science 41 (2006) 4871-4875.

[34] G. Caylı, S. Küsefoğlu, Increased yields in biodiesel production from used cooking oils by a two step process: comparison with one step process by using TGA, Fuel Processing Technology 89 (2008) 118-122.

[35] A.E. Galetti, M.F. Gomez, M.A. Arrúa, M.C. Abello, Hydrogen production by ethanol reforming over NiZnAl catalysts-influence of Ce addition on carbon deposition, Applied Catalysis A: General 348 (2008) 94-102.

[36] B. Freedman, E.H. Pryde, T.L. Mounts, Variables affecting the yields of fatty esters from transesterified vegetable oils, JAOCS 61 (1984) 1638-1643.

[37] B. Ma, L.D. Clements, M.A. Hanna, The effects of catalyst, free fatty acids, and water on transtestification of beef tallow, American Society of Agricultural Engineers 41 (1998) 1261-1264.

[38] M.K. Lam, K.T. Lee, Mixed methanol-ethanol technology to produce greener biodiesel from waste cooking oil: a breakthrough for $\mathrm{SO}_{4}^{2-} / \mathrm{SnO}_{2}-\mathrm{SiO}_{2}$ catalyst, Fuel Processing Technology 92 (2011) 1639-1645.

[39] O. Shu, J. Gao, Z. Nawaz, Y. Liao, D. Wang, J. Wang, Synthesis of biodiesel from waste vegetable oil with large amounts of free fatty acids using a carbon-based solid acid catalyst, Applied Energy 87 (2010) 2589-2596.

[40] K. Nakamoto, Infrared and Raman Spectra of Inorganic and Coordination Compounds, sixth ed. Wiley, New York, 2009. 